\title{
Research on the New Mode of "Internet+ Combination of Medical Treatment and Endowment" Aged Care Service Industry
}

\author{
Bai Hong ${ }^{a}$ and Liu Libing* \\ Department of Medical Science Research Center, Peihua University, Xi'an, 710125, China \\ a357435305@qq.com \\ *corresponding author
}

Keywords: Internet, medical care, pension model.

\begin{abstract}
With the increasing of the aging degree of our country, pension problem has gradually become the focus of national attention. The "Internet + combination of medical treatment and endowment” pension model is gradually being accepted by more and more elderly people, making it an inevitable choice for China's pension industry. This paper explores and discusses the development model of the modern pension service industry that integrates "Internet + combination of medical treatment and endowment", and points out the current development trend and advantages of China's pension service industry model in order to provide new ideas for promoting the sustainable development of this new type of modern pension service industry model.
\end{abstract}

\section{Introduction}

Since 1999, China has entered the aging stage. By 2017, the number of elderly people over the age of 60 has reached more than 200 million in China, accounting for more than $15 \%$ of the total population. The pension problem in our country has become a major issue related to the national economy and people's livelihood ${ }^{[1]}$. Faced with such a severe ageing phenomenon, the problem of elderly care and medical care has become a main source of problems for many families.

Due to the urgent demand of the elderly for "having a good old-age and getting old medicine", the traditional old-age care model has been unable to fully meet the dual needs of the elderly for care services and medical services. Existing primary medical resources are far from meeting the needs in elderly care facilities and the older patients are unable to enjoy quality medical resources in medical institutions in the community ${ }^{[2]}$. In recent years, a new type of old-age care model combination health care and pension gradually being accepted by more and more elderly people and becomes an inevitable choice for the old-age care industry in China. The combination of medical care and health care is not a simple superposition of medical care and pensions, but the integration of medical resources into pension services, which will not only satisfy elderly care services but also provide basic medical service needs for the elderly ${ }^{[3]}$. "The combination of medical treatment and endowment " mainly includes three interrelated stages, the first is disease prevention before illness, the second is convenience in illness, and the third is rehabilitation care after illness ${ }^{[4]}$. At present, the new old-age care model, in which medical care and pension care are integrated with each other, is still at the exploratory stage. At the same time, its development status also reveal many problems as follows. Such as the low informationization degree of the combination of medical treatment and pension, the lack of a long-term effective platform for cooperation and exchange, the lack of elderly information databases and physical health data which hindering the development of personalized services, the lack of sharing of data and resources among pension service agencies causing a waste of medical and pension resources and is detrimental to the sustainable development of the pension service industry, imperfect mutual integration system between medical and pension care and so on.

In order to unravel the closed, disorderly, and single model of traditional medical care and pension care combined with the service industry, the Internet has gradually penetrated into the pension service industry. With the gradual emergence of the Internet, Internet of Things, intelligent products, the "Internet +" intelligence products have gradually been integrated into all aspects of the 
pension services, which are bringing revolutionary change to medical services and pension services. ${ }^{[5]}$. The development of intelligent old-age care is in line with the requirements of economic and social development. The excellent development of modern information technology also brings many advantages to the realization of the mutual combination of medical care and pension. The core of the medical association is the reform of the medical service production mode in the Internet age $\mathrm{e}^{[6]}$.

The "Internet + combination of medical treatment and endowment" pension model aims to upgrade traditional medical work to a medical system based on "big data processing functions" and "community information gathering", and help the elderly to realize the statistics of daily health information through service terminals. And then form a complete database of medical and health information, enabling better management of health information for the elderly, and then providing more scientific, true and richer information foundation for disease identification, disease progression analysis and medicare programs to ensure the accuracy and effectiveness of medical work $^{[7]}$.

\section{Advantages of the new pension model of "Internet + medical care and pensions combined with each other"}

Through the application of the Internet, each pension institution can share information, and through the cooperation with medical institutions, resources can be shared among pension institutions ${ }^{[8]}$.

The participation of the Internet makes it possible for the aged care institutions not only to take care of the elderly and provide them with high-security medical conditions, but also to meet the needs of the elderly in cultural entertainment, meanwhile filling in the loneliness of being away from

Expanded the consumer market. The "Internet + medical care and pensions combined with each other" pension service model is not limited to the traditional conservation industry. It also promotes the development of the medical industry and the financial industry, enabling the reuse of medical and nursing staff and promote sales of health products and health equipment for the elderly.

The use of "Internet +" can greatly ease the problem of information asymmetry, giving full play to the leading role of large hospitals, and promote the coordinated development of medical and pension for every member of the service chain, improving the accuracy and efficiency of medical resources, and reduce the waste of resources ${ }^{[9]}$.

"Internet+ combination of medical treatment and endowment" can solve the problem of inadequate supply and distribution of community medical resources and improve the service quality of the community care for the elderly. Besides, it can also expand the scope of community care services and provide strong support for the development of the primary medical care and pension industry. It is very necessary to integrate the medical community with the resources of community care institutions through information services ${ }^{[10]}$.

\section{The Problems Faced in the Development of the Model of "Internet+ combination of medical treatment and endowment"}

The application of the Internet in the development of the modern pension service industry is not so popular that it cannot fully play its due role.

Most of the elderly people are skeptical about the combination of medical care and pensions under the "Internet" conditions, which may be attributed to the fact that the elderly people have less touch with electronic devices and they are not capable of mastering the use of electronic products ${ }^{\text {[11] }}$. According to the survey, as of December 2015, the proportion of elderly people using the Internet is only about $2 \%$ in China ${ }^{[5]}$. It can be observed that the Internet is still a platform with young people as the main player. Only a few elderly people know or have access to the Internet. This undoubtedly caused a great obstacle to the promotion of this new model of old-age care services.

The mutual development of medical care combining with pension will inevitably require the 
improvement of the nursing market. However, the current level of care services and service quality are still uneven. Nursing personnel are not familiar with the technologies and products of the Internet + medical care and pension integration, which directly have an impact on the demand for nursing care services.

\section{Solutions for the development of "Internet+ combination of medical treatment and endowment"}

Increasing government support and improve top-level design. The state is one of the major providers of social security systems. In order to promote the healthy development of the "Internet+ combination of medical treatment and endowment" pension model, the most important task at present is to increase support and improve the top design from the government's point of view. First, the country must formulate specific policies and methods. Increase efforts to formulate an action plan, and issue specific relevant policy documents to provide a guiding framework for the development of this new type of old-age care model in terms of major goals, key tasks, and implementation plans. Second, we must establish a sound financing mechanism. The old-age service project is an important issue concerning the quality of people's livelihood. We must increase government investment, and at the same time mobilize all sectors of society to participate in the construction of this new model of old-age care mode, and set up a diversified financing model involving governments, institutions, communities, enterprises and other organizations. Then explore investment models in which the government and social capital cooperate with each other.

Strengthenning the construction of an environment suitable for the elderly. At present, the rapid development of modern information technologies such as the Internet, the Internet of Things, big data, and cloud computing provides technological support for intelligent old-age care. We should establish an appropriate old network environment based on this reality. Faced with the current situation that the elderly have a low rate of Internet penetration, we should develop electronic devices and simple APPs that are suitable for usage by the elderly, so that the main body of this intelligent old-age care service - the elderly — can really enjoy the convenience brought by this new type of internet old-age care model, and has actually experience the convenience brought by the Internet in their old age.

Through the use of Internet technology and methods to gradually realize the overall utilization of medical resources, helping community hospitals to provide a more robust hardware guarantee for community care.

Strengthenning cross-border cooperation to promote the development of Internet healthcare, and enable Internet companies to give full play to the important role of accelerators and connectors in ecological development by building strong technology reserves, including leading Internet technologies and services such as big data, smart terminals, open platforms and cloud platforms.

Developing more mobile medical devices to meet the needs of the elderly. Through online data, offline promotion, mobile terminals and other multi-channels to broaden the mutual combination of medical care and pension for the market to meet the growing demand for medical care services, and thus promote the sustainable development of medical care and pension model.

Developing more mobile medical devices to meet the needs of the elderly. Through online data, offline promotion, mobile terminals and other multi-channels to broaden the mutual combination of medical care and pension for the market to meet the growing demand for medical care services, and thus promote the sustainable development of medical care and pension model.

\section{Conclusion}

As a kind of old-age care model, the combination of medical and health care is gradually accepted by the elderly. The application of "Internet +" provides a new platform for this new type of care for the elderly. This article analyzes the advantages of the "Internet + medical care and pensions combined with each other" pension model and the challenges it faces in the actual operation from multiple perspectives. In light of this opportunity and challenge, this paper proposes 
basic ideas and measures for the development of this new type of old-age care model.

\section{Acknowledgements}

This work was financially supported by Xi'an Social Science Planning Project Peihua special fund (16PH05).

\section{References}

[1] He Taiwei, Based on the research of the pension mode under the combination of medical care and health.Yunnan University of Finance and Economics, 2017.

[2] ZHANG Lei, GU Min, WANG Xiaodong, WEI Wei. Development Strategy on Regional Medical Association. Chinese Health Quality Management, 2014,21(02):74-76.

[3] HUANG Shanshan. Analysis of the Influence of "Internet + " on the pension mode of Combination of medical treatment and endowment. Journal of Chifeng University(Natural Science Edition). 2017,33(13):33-34.

[4] LIU Yunjie, WANG Yanhong, ZHANG Zhiyong, RUAN Wei, ZHU Jianguo, ZHANG Fengyan, LIU Yibing, SUN Qianmei, ZHANG Wei, ZHANG Lin. Two-way referral path for hospitalized patients in tertiary hospitals and community hospitals. Chinese General Practice Medicine, 2010,13(07):701-703.

[5] SUI Dang Chen, ZHANG Ting. The Research for "Internet+ Medical-Nursing Combined" Pension Mode Development. Scientific Research on Aging, 2017,5(05):60-68.

[6] Li Qian, LI Fengru, SHI Peina, LIU Jian. Explore effective ways to implement the medical association. Hospital Dean Forum - Journal of Capital Medical University (Social Sciences Edition), 2014,11(02):47-51.

[7] LI Mo, GUO Rui, Zhao Jian. Research on the combination of medical care and support for the elderly in the perspective of "Internet +". The Latest Medical Information Digest in the World, 2016,16(99):177-181.

[8] JI Chenguang. Discussion on the Mode of Development of the Modern Service Industry for the Aged in "Internet+Medicine and Health+Finance". Shanxi Agricultural Economics, 2017(16):25-26.

[9] JIN Ai-xiang. Exploration of Community-based Medical Care and Medical Resource Distribution in Zhejiang Province under the Internet+. Chinese Journal of Rural Medicine, 2016,23(21):61-62.

[10] YU Guoying, LE Jiayi, LIAN Yuanyuan. The feasibility research of the exploration and construction of the elderly health management under the service mode of the medical service combined with endowment service. Shanghai Medical \& Pharmaceutical Journal, 2016,37(02):4749.

[11] DU Shaoying, WANG Yan, Zhou Yi et al. Study on the Demands for “Internet Plus” HomeBased Medical-Nursing Combined Service for the Elderly. Hebei Medicine, Hebei Medicine, 2017,23(10):1744-1747. 